\title{
Dry sliding wear performance of AA7075/MoS2 composite materials
}

\author{
R. Kousik Kumaar*, K. Somasundara Vinoth* and M. Kavitha** \\ *Department of Production Engineering, PSG College of Technology, Coimbatore 641 004, Tamilnadu, India \\ **Department of Metallurgical Engineering, PSG College of Technology, Coimbatore 641 004, Tamilnadu, India \\ Corresponding Author: kousikkumaarphd@gmail.com
}

Submitted : 27/08/2020

Revised : 26/08/2021

Accepted :06/09/2021

\begin{abstract}
This article aims at exploring the dry sliding wear performances on the aluminum (AA7075) metal matrix composites reinforced with molybdenum disulfide, which is a solid lubricant using response surface methodology (RSM). Specific Wear Rate (SWR) for the AA7075 pure alloy, AA7075+2wt\% molybdenum disulfide, and AA7075+4wt $\%$ molybdenum disulfide were measured according to ASTM G99 standards in pin-on-disc apparatus. Design of experiments was selected with changed parameters like the varying percentage of molybdenum disulfide $(\%)$, applied load $(\mathrm{N})$, and sliding velocity $(\mathrm{m} / \mathrm{s})$ based on Central Composite Design in response surface methodology, considering them as continuous factors. Experiments for the specific wear rate of pure alloy and the composites were conducted. The volume loss was measured using the pin-on-disc apparatus from which the specific wear rate value was calculated. The obtained results are analyzed, and a mathematical model was formulated using the response surface methodology. The optimum level parameters for the specific wear rate have been identified, and the results of the experiment specify that the sliding velocity and molybdenum disulfide percentage have a substantial role in controlling the wear behavior of composites when compared with the other parameter. The optimum condition for the specific wear rate was identified and experimented with for studying the result.
\end{abstract}

Keywords: AA7075; Dry sliding wear; Molybdenum disulphide; Response surface methodology; Specific wear rate.

\section{INTRODUCTION}

A composite material is a combination of materials engineered with the intent of gaining the finest characteristic of the respective material. The options for achieving a composite microstructure by self-reinforcement are largely limited. Generally, in a metal matrix composite material, ceramic reinforcements are considerably used compared with continuous fiber reinforcement. Metal matrices include pure as well as alloys of aluminum, magnesium, nickel, titanium, copper, and other metals. The powders used as the reinforcement were typically equiaxed (roughly spherical), like a grain of sand, and between 0.5 and $40 \mu \mathrm{m}$ in diameter (Evans et al., 2003)

The most common type of reinforcement is usually the silicon carbide or alumina, which serves as a traditional way of reinforcing the MMCs. But the unconventional way of producing an MMC depends upon the reinforcement used. One such way of producing an MMC is using a solid lubricant, like molybdenum disulfide (MoS2). The 
lubricating properties of MoS2 have paved the way for utilizing them in the reinforcements of metal matrix composite materials. The MoS2 particles show better results in improving the wear resistance of the composite material compared to the as-cast alloy (Alidokht et al., 2013; Somasundara Vinoth et al., 2012). The improvement in the wear resistance in the composite material was due to the formation of a rich film layer on the wear surface due to the dry sliding behavior, which restricts the plastic deformation of the material (Alidokht et al., 2013; Somasundara Vinoth et al., 2012; Hemendra Patle et al., 2019).

A tribo-layer was formed in these composites, and the formation of the layer is owing to the presence of MoS2; the layer which forms over the pin avoids the direct contact of the aluminum to the disc (Anish Rajan and Shanmugasundram 2019). Also, the minimum wear rate is obtained due to the formation of strain fields around the reinforcement (Anish Rajan and Shanmugasundram 2019). The fine dispersion of the reinforcement in the matrix is vital for improving the tribological properties and also the hardness of the composite as the homogeneous dispersion of the reinforcement in the matrix gives an obstacle to the dislocations that occur in the material structure (Alidokht et al., 2013; Somasundara Vinoth et al., 2012; Siddesh Kumar et al., 2014; Anish and Ananth Kumar, 2018; Jojith and Radhika, 2019). Even though the hardness increases due to the fine dispersion of the reinforcement in the matrix, it does not favor the improvement of tensile or yield strength of the composite, as the reinforcement causes a mixedmode, which is in Ductile-Brittle regions (Somasundara Vinoth et al., 2012). Sometimes, as an individual factor, the reinforcement improves the yield and tensile strength but does not favor the elongation properties (Jojith and Radhika, 2019; Bhargavi Rebba and Ramanaiah, 2014; Subba Rao and Ramanaiah, 2017). As a whole, the density of the composite increases as the density of the molybdenum disulfide reinforcement is high compared to aluminum alloy and other reinforcements in hybrid conditions (Alidokht et al., 2013; Somasundara Vinoth et al., 2012).

The reinforcement particles in the composites, which obstruct the motion of the atoms, offer great resistance to the plastic deformation and also increase the grain boundary strength, which increases the hardness of the composites. Wear rate was very low at the condition of lower loads as the surface interaction pressure is less. Load increment increases the wear rate due to the stresses building up and results in more material removal (Jojith and Radhika, 2019).

The factors like applied load, sliding velocity, and weight percentage of the reinforcement influence the wear resistance of the composite. The specific wear rate (SWR) and Coefficient of Friction (COF) are the responses of these factors where the most noteworthy influence is due to the percentage of MoS2 followed by sliding velocity and applied load for SWR, and in the case of COF, the applied load contributes more, followed by the percentage of MoS2 and sliding velocity. The percentage of MoS2 influences the topmost priority for both SWR and COF, followed by sliding velocity and applied load (Dharmalingam et al., 2011).

Based on the major studies in the metal matrix composites, it was found that the study on the mechanical and tribological characteristics of AA7075 aluminum alloy with Molybdenum disulfide as the reinforcement is not much endeavored. Hence, an attempt was made to synthesize AA7075/MoS2 MMC, and the wear behavior of the composites under dry sliding conditions was analyzed through RSM to attain an optimum wear condition.

\section{MATERIALS AND METHODS}

The 7xxx series of aluminum alloys are generally termed as 'hard' alloys among the other alloys of aluminum. Aluminum alloy 7075 has zinc-magnesium-copper as the following alloying constituents next to aluminum. Aluminum alloy 7075 of series 7xxx was taken as the matrix material, and the solid lubricant Molybdenum disulfide $\left(\mathrm{MoS}_{2}\right)$ was taken as the reinforcement. 
The chemical composition of the AA7075 alloy used is shown in Table 1. A stir casting technique was implemented for producing the composites. Molybdenum disulfide in varying amounts ranging between 0 wt.\%, 2 wt. $\%$, and 4 wt. $\%$ was reinforced with aluminum 7075 alloy, and the weight percentages of the reinforcement were not chosen beyond $4 \mathrm{wt} . \%$ because the mechanical and tribological properties of the composites were not favorable beyond the considered percentages (Bhargavi Rebba and Ramanaiah, 2014).

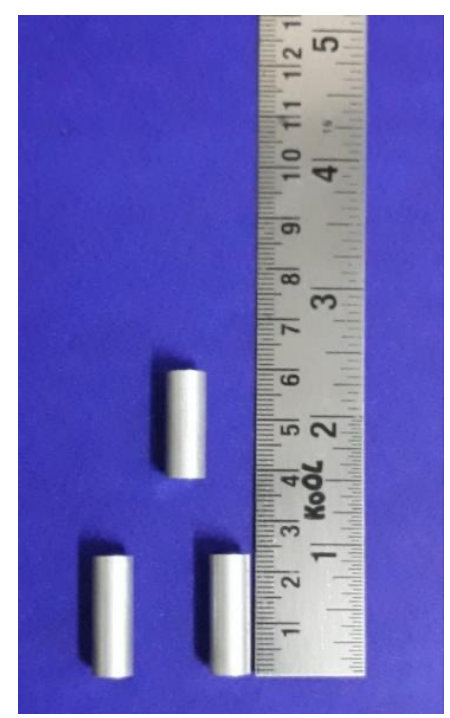

Figure 1. Photograph of composite pins of dimensions $\varnothing 8 \mathrm{~mm} \times 24 \mathrm{~mm}$ for the wear test.

The cast composite pins for performing the dry sliding wear test were machined to the dimension of $\varnothing 8 \mathrm{~mm} \times 24$ $\mathrm{mm}$ (Figure 1), and it was performed on the Magnum Engineers pin-on-disc apparatus system. The pin-on-disc wear and friction testing machine linked to a data collection system are shown in Figure 2.

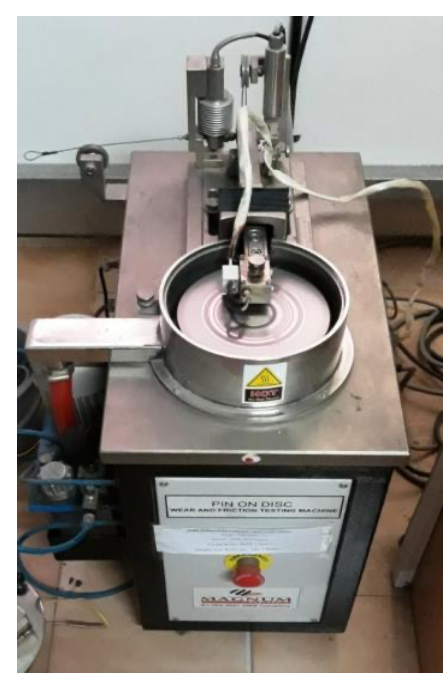

Figure 2. Photograph of pin-on-disc apparatus. 
The apparatus consists of a stationary pin sliding on a rotating disc driven by an electric motor. The disc material was EN32 steel. The pins are polished; their weights are measured with an electronic balance of $0.0001 \mathrm{~g}$ precision. Wear tests were carried out at normal room temperature $\left(30 \pm 3{ }^{\circ} \mathrm{C}\right)$ under the dry sliding condition as per the ASTM G99 standard. Before the commencement of the test, all the contacting surfaces were polished to a metallurgical finish, cleaned, and dried. The sliding distance of $1000 \mathrm{~m}$ was taken as a fixed parameter. The wear loss of the specimens was measured by the weight loss method. The difference between the weights measured before and after the test provides the wear loss of the composites in terms of weight loss, and it was converted into the volume loss by dividing with the theoretical density of the composite. Specific wear rate (Ws) was calculated using equation (1), where $\Delta \mathrm{V}$ terms the volume loss.

$W_{S}=\frac{\Delta V}{L O A D \times S L I D I N G \text { DISTANCE }} \mathrm{mm}^{3} / \mathrm{Nm}$

Table 1. Chemical Composition of AA7075 (wt \%).

\begin{tabular}{|c|c|c|c|c|c|c|c|c|c|}
\hline $\mathrm{Si}$ & $\mathrm{Fe}$ & $\mathrm{Cu}$ & $\mathrm{Mn}$ & $\mathrm{Mg}$ & $\mathrm{Zn}$ & $\mathrm{Pb}$ & $\mathrm{Ni}$ & $\mathrm{Ti}$ & $\mathrm{Al}$ \\
\hline 0.45 & 0.19 & 1.55 & 0.043 & 1.62 & 4.98 & 0.004 & 0.008 & 0.05 & 90.91 \\
\hline
\end{tabular}

DoE was employed in formulation using the three variable factors like weight percentage of $\mathrm{MoS}_{2}$, applied load, and sliding speed for a constant sliding distance of $1000 \mathrm{~m}$ as shown in Table 2. A three-level Central Composite design was adapted, which is represented in Table 2.

The upper limit of the process variable was coded as ' +1 ' and the lower limit as ' -1 '. In the present study, three parameters, namely, sliding velocity (SV), applied load (L), and weight percentage of $\mathrm{MoS}_{2}(\mathrm{M})$, were chosen as the variables. Dry sliding wear tests were conducted for 20 different conditions obtained using Central Composite Design as shown in Table 3 .

Table 2. Experimental factors and their levels based on DoE.

\begin{tabular}{|c|c|c|c|c|c|c|}
\hline \multirow{2}{*}{ Factor } & \multicolumn{2}{|c|}{ Notation } & \multicolumn{2}{c|}{ Factor Level } \\
\cline { 2 - 3 } & Natural & Coded & & -1 & 0 & 1 \\
\cline { 2 - 6 } Weight percentage of $\mathrm{MoS}_{2}$ & $\% \mathrm{MoS}_{2}$ & $\mathrm{X}_{1}$ & $\%$ & 0 & 2 & 4 \\
\hline Load applied & $\mathrm{Load}$ & $\mathrm{X}_{2}$ & $\mathrm{~N}$ & 10 & 20 & 30 \\
\hline Sliding Velocity & $\mathrm{SV}$ & $\mathrm{X}_{3}$ & $\mathrm{~m} / \mathrm{s}$ & 1 & 2 & 3 \\
\hline
\end{tabular}


Table 3. Central Composite Design of experiment matrix for a wear test of AA7075/MoS 2 composite material.

\begin{tabular}{|c|c|c|c|c|c|c|c|}
\hline \multirow{3}{*}{$\begin{array}{l}\text { Exp. } \\
\text { No }\end{array}$} & \multicolumn{3}{|c|}{ Coded } & \multicolumn{3}{|c|}{ Natural } & \multirow{2}{*}{$\begin{array}{c}\text { Specific Wear } \\
\text { Rate }\end{array}$} \\
\hline & \multirow{2}{*}{$\mathrm{X}_{1}$} & \multirow{2}{*}{$\mathrm{X}_{2}$} & \multirow{2}{*}{$\mathrm{X}_{3}$} & $\% \mathrm{MoS}_{2}$ & LOAD & SV & \\
\hline & & & & $(\%)$ & $(\mathrm{N})$ & $(\mathrm{m} / \mathrm{s})$ & $\times 10^{-3}\left(\mathrm{~m}^{3} / \mathrm{Nm}\right)$ \\
\hline 1 & -1 & -1 & -1 & 0 & 10 & 1 & 0.2929 \\
\hline 2 & -1 & -1 & 1 & 0 & 10 & 3 & 1.3214 \\
\hline 3 & -1 & 0 & 0 & 0 & 20 & 2 & 0.8679 \\
\hline 4 & -1 & 1 & -1 & 0 & 30 & 1 & 0.2655 \\
\hline 5 & -1 & 1 & 1 & 0 & 30 & 3 & 1.1762 \\
\hline 6 & 0 & -1 & 0 & 2 & 10 & 2 & 0.0496 \\
\hline 7 & 0 & 0 & -1 & 2 & 20 & 1 & 0.0567 \\
\hline 8 & 0 & 0 & 0 & 2 & 20 & 2 & 0.0142 \\
\hline 9 & 0 & 0 & 0 & 2 & 20 & 2 & 0.0832 \\
\hline 10 & 0 & 0 & 0 & 2 & 20 & 2 & 0.0832 \\
\hline 11 & 0 & 0 & 0 & 2 & 20 & 2 & 0.0832 \\
\hline 12 & 0 & 0 & 0 & 2 & 20 & 2 & 0.0832 \\
\hline 13 & 0 & 0 & 0 & 2 & 20 & 2 & 0.0832 \\
\hline 14 & 0 & 0 & 1 & 2 & 20 & 3 & 0.5065 \\
\hline 15 & 0 & 1 & 0 & 2 & 30 & 2 & 0.0449 \\
\hline 16 & 1 & -1 & -1 & 4 & 10 & 1 & 0.1791 \\
\hline 17 & 1 & -1 & 1 & 4 & 10 & 3 & 0.3126 \\
\hline 18 & 1 & 0 & 0 & 4 & 20 & 2 & 0.3688 \\
\hline 19 & 1 & 1 & -1 & 4 & 30 & 1 & 0.1264 \\
\hline 20 & 1 & 1 & 1 & 4 & 30 & 3 & 0.3395 \\
\hline
\end{tabular}




\section{RESULTS AND DISCUSSION}

The microstructure of the composite materials, as well as that of the pure alloy, was studied through an SEM microimage acquired from the Field Emission Scanning Electron Microscope (FE-SEM) SIGMA HV-Carl Zeiss with Bruker Quantax 200-Z10 EDS Detector. The Energy-Dispersive X-ray Spectroscopy (EDS) analysis was also carried out to find the chemical characterization of the composites in the same machine. The results of the SEM microimage of AA7075+2wt.\% MoS2 and AA7075+4wt.\% MoS2 (Figure 3 and Figure 4) reveal the presence of the reinforced MoS2, which is disturbed uniformly in AA7075+2wt.\% MoS2 as well as AA7075+4wt.\% MoS2 composite materials. Also, the SEM microimage reveals the presence of $\mathrm{Al} 7 \mathrm{Cu} 2 \mathrm{Fe}$, which is like a dendritic arm formation.

Furthermore, the presence of the MgZn2 compound can also be traced. Uniform dispersion of the reinforcement in the matrix phase has reduced the reinforcement's cluster formation and micro porosities, which in turn enhance the mechanical properties; similar results were observed in the previous works of Jojith and Radhika (2019). The Energy-Dispersive X-ray Spectroscopy (EDS) analysis (Figure 5 and Figure 6) reveals the traces of the molybdenum disulfide reinforcement at moderate peak level, which confirms the particle reinforcement's presence in the metal matrix. The EDS also reveals the presence of Zn-Mg in high peaks, confirming the 7XXX series of the aluminum alloy.

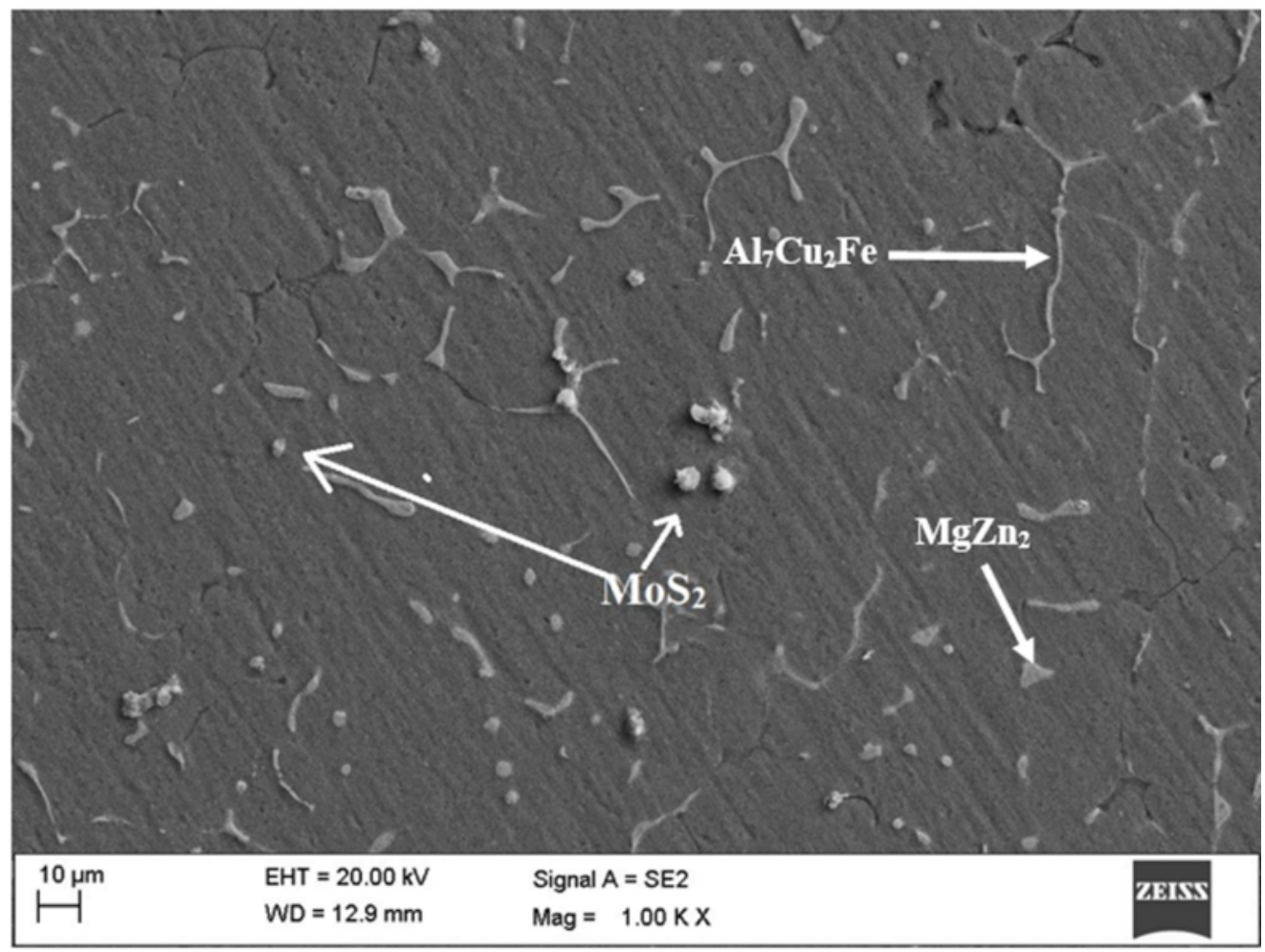

Figure 3. FESEM microimage of the microstructure of AA7075+2wt.\% $\mathrm{MoS}_{2}$. 


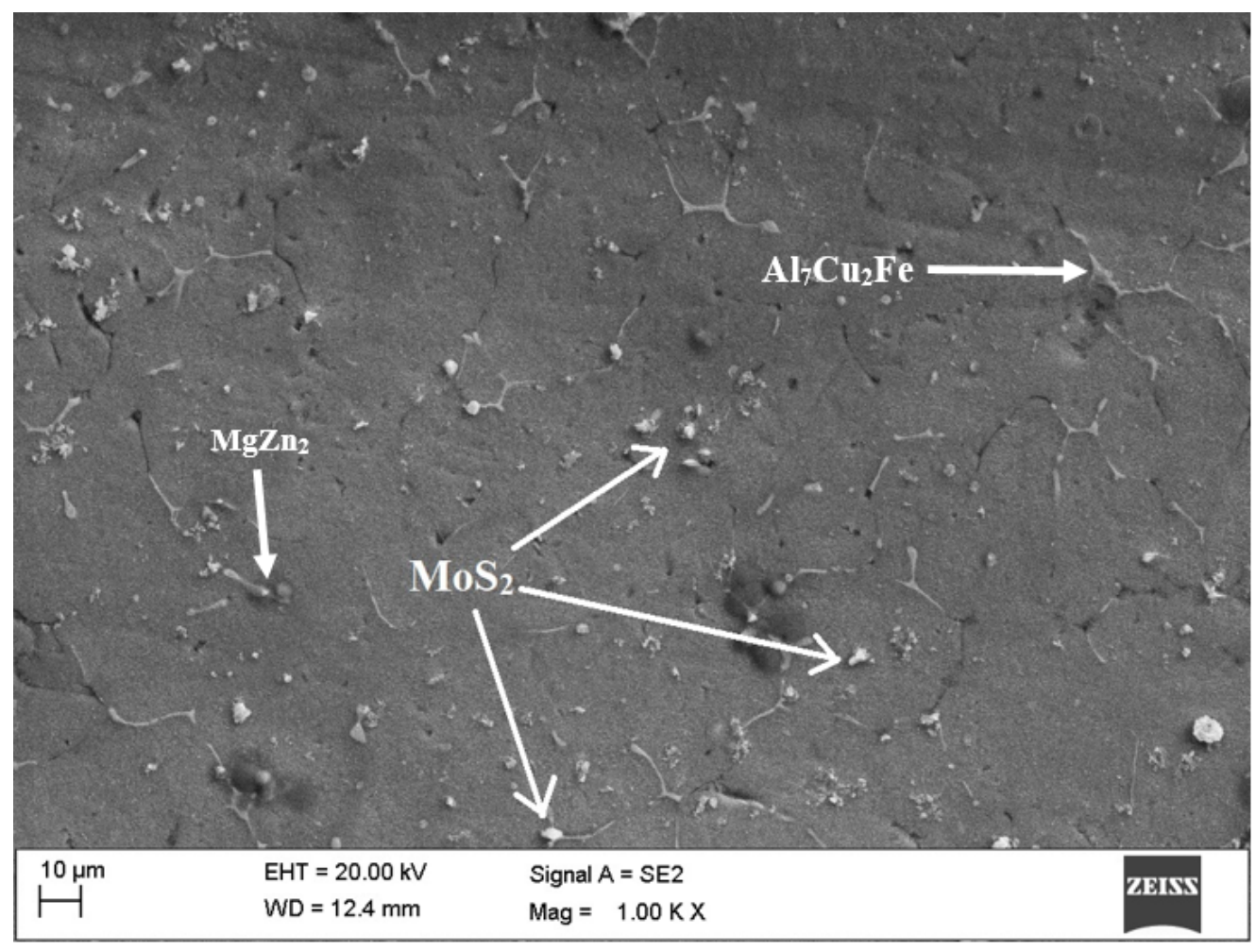

Figure 4. FESEM microimage of the microstructure of AA7075+4wt.\%MoS2.

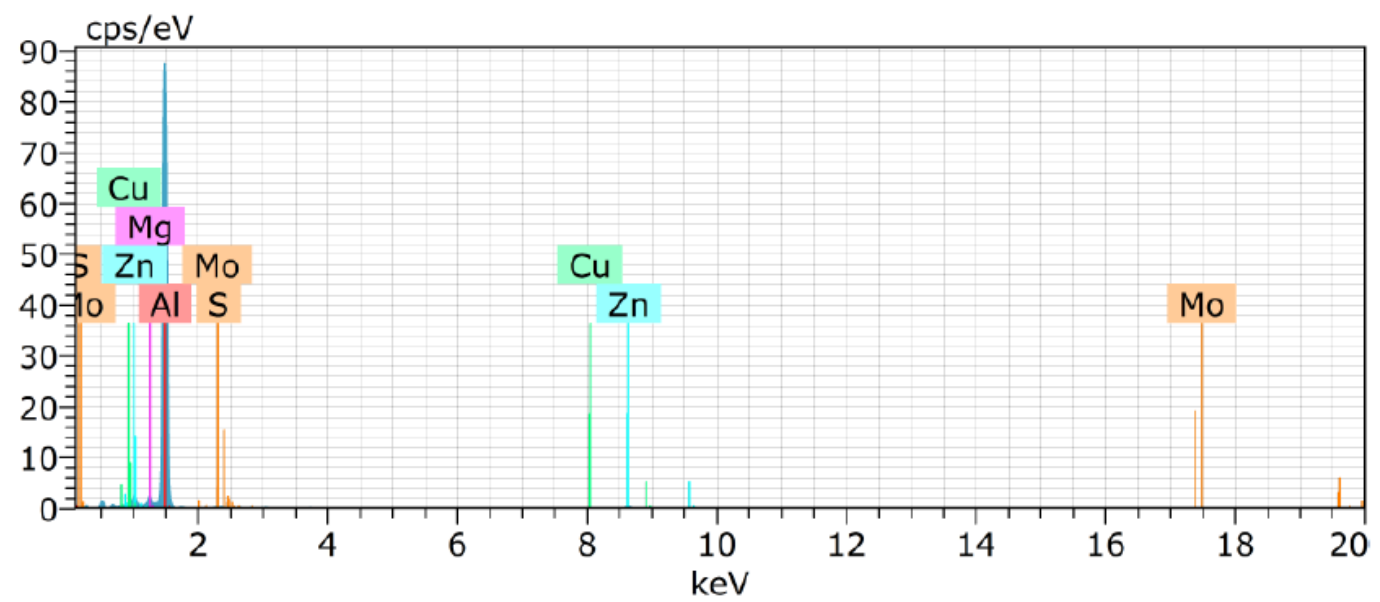

Figure 5. EDS graph for AA7075+2wt.\%MoS2. 


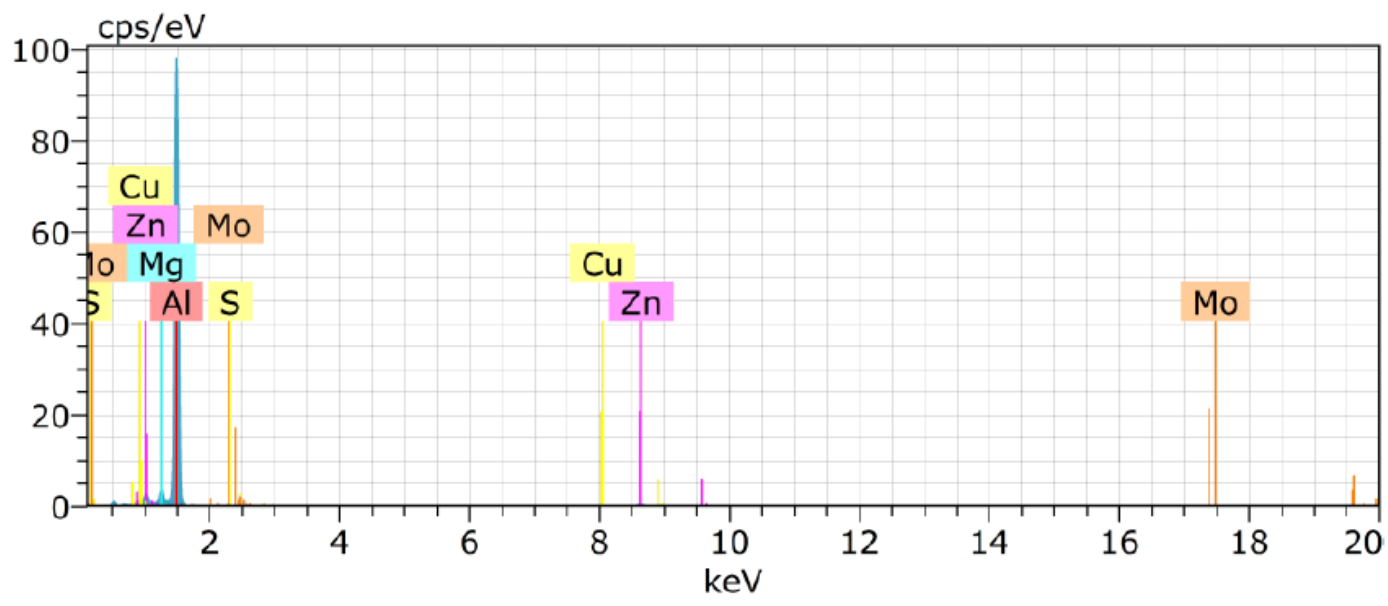

Figure 6. EDS graph for AA7075+4wt.\%MoS 2 .

From Table 4, it is shown that the percentage of the $\mathrm{MoS}_{2}$ is contributing to a maximum of about $24.75 \%$ in linear terms, and $\mathrm{MoS}_{2}$ contributes to another $19.24 \%$ as square terms summing to a total of $44 \%$. It can be seen from Figure 7 that the specific wear rate decreases and then slightly increases with the content of reinforcement, which increments from $0 \mathrm{wt} . \%$ to $4 \mathrm{wt} . \%$.

The decrease of SWR at $2 \mathrm{wt} . \%$ of $\mathrm{MoS}_{2}$ in the aluminum matrix is due to the formation of a tribo-layer by the solid lubricant in the surface of the composite, which acts as a key factor in averting the wear of the composites. A similar effect has been found in preceding works (Kanathavel et al., 2016; Monikandan et al., 2017; David Joseph et al., 2018), but the condition changes with the further increase in the $\%$ of $\mathrm{MoS}_{2}$, and the SWR slightly increases at 4 wt.\% similar to Kanathavel et al. (2016), which might be due to particle nature of $\mathrm{MoS}_{2}$, which is a soft particle reinforcement.

The effect of the sliding velocity factor contributes to $27.45 \%$ (Table 4 ) on specific wear rate, as in the linear term. This reveals that sliding velocity plays a major role in affecting the specific wear rate of the composite, which was mentioned by Dharmalingam et al. (2010) in their study. From Figure 7, it was observed that the specific wear rate rises slowly with an increase in sliding velocity. With an increase in sliding velocity from $1 \mathrm{~m} / \mathrm{s}$ to $3 \mathrm{~m} / \mathrm{s}$, the specific wear rate increases because of the friction creating a temperature rise between the surfaces causing the composite material to soften and undergo severe plastic deformation and also the increase in SWR might be due to the crushing of the $\mathrm{MoS}_{2}$ at higher sliding velocity as observed by Jojith and Radhika (2019).

The interaction mean plot (Figure 8) shows that the model is having a two-way interaction between $\mathrm{MoS}_{2}$ and sliding velocity alone and the interaction between $\mathrm{MoS}_{2}$ with sliding velocity factors contributing to $11.63 \%$ respectively, which in turn reveals that the major contribution to the specific wear rate is sliding velocity followed by the percentage of the reinforcement, and the equivalent results were witnessed by Dharmalingam et al. (2010). It may be observed that the combined effect of $\mathrm{MoS}_{2}$-sliding velocity decreases the SWR considerably. This may be due to linear terms $\%$ of $\mathrm{MoS}_{2}$ and sliding velocity, which contributes to the maximum effect and because of the less significance, the applied load in the model does not have interactions with either $\mathrm{MoS}_{2}$ or Sliding velocity, so the interaction between $\mathrm{MoS}_{2}-$ load and sliding velocity-load was not observed (Figure 8).

SWR is not considerably affected by the applied load. It is observed from Figure 7 that SWR increases and then decreases gradually on an increased applied load. It is also indicated in ANOVA that the applied load variable is not 
significant in terms of specific wear rate from Table 4 , as the P-value for the load factor is $>0.05$, but the square terms of load seem to be significant but contribute to a very small percentage, and hence, the load factor is not significantly considered, and this may be due to condition that the reinforcement $\mathrm{MoS}_{2}$ added to the aluminum matrix can bear the applied load.

Table 4. Analysis of variance for specific wear rate $\times 10-3(\mathrm{~m} 3 / \mathrm{Nm})$.

\begin{tabular}{|c|c|c|c|c|c|}
\hline Source & Adj SS & Adj MS & F-Value & P-Value & $\%$ Contribution \\
\hline M & 0.67469 & 0.674688 & 138.4 & 0.000 & 24.75 \\
\hline $\mathrm{L}$ & 0.00412 & 0.004125 & 0.85 & 0.376 & 0.15 \\
\hline SV & 0.74834 & 0.748344 & 153.51 & 0.000 & 27.45 \\
\hline $\mathrm{M}^{*} \mathrm{M}$ & 0.52464 & 0.524639 & 107.62 & 0.000 & 19.24 \\
\hline $\mathrm{L}^{*} \mathrm{~L}$ & 0.0496 & 0.049601 & 10.17 & 0.008 & 1.82 \\
\hline $\mathrm{SV}^{*} \mathrm{SV}$ & 0.02752 & 0.027522 & 5.65 & 0.035 & 1.01 \\
\hline $\mathrm{M}^{*} \mathrm{SV}$ & 0.31712 & 0.317117 & 65.05 & 0.000 & 11.63 \\
\hline Error & 0.0585 & 0.004875 & - & - & - \\
\hline Lack-of-Fit & 0.05453 & 0.007789 & 9.8 & 0.012 & - \\
\hline Pure Error & 0.00397 & 0.000795 & - & - & - \\
\hline Total & 2.72649 & - & - & - & - \\
\hline
\end{tabular}




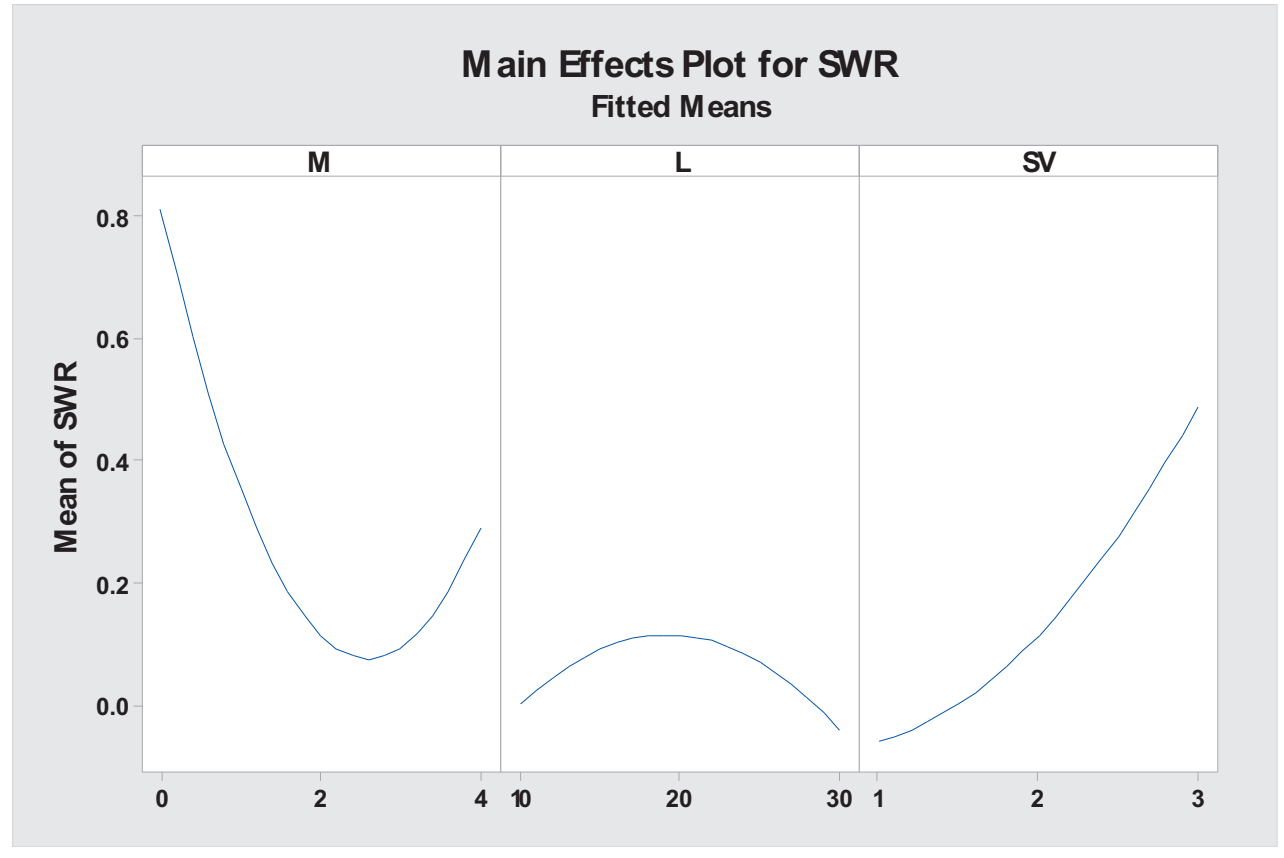

Figure 7. Main effect plot of specific wear rate for AA7075+MoS2 composites.

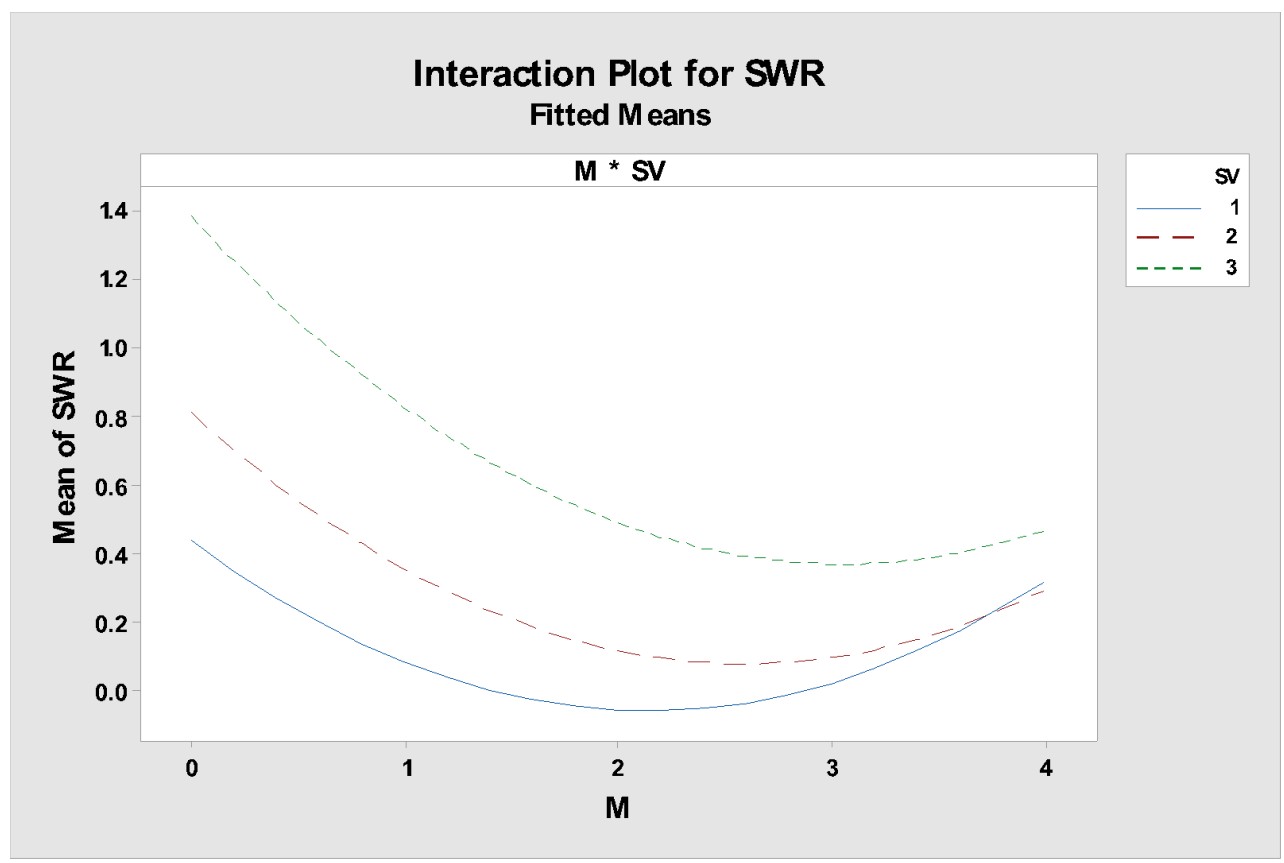

Figure 8. Interaction plot of specific wear rate for $\mathrm{AA} 7075+\mathrm{MoS}_{2}$ composites. 
Comparing the SEM microimages of AA7075, AA7075+2wt. $\% \mathrm{MoS}_{2}$, and AA7075+4wt. $\% \mathrm{MoS}_{2}$ at the applied condition $20 \mathrm{~N}$ and $2 \mathrm{~m} / \mathrm{s}$, Figure 9 shows the unreinforced aluminum alloy has experienced layer ploughing and delamination with crater, which indicates that the wear mechanism is adhesive wear, and similar results were perceived by Mohammad Rouhi et al. (2019). The reinforced aluminum alloy with $2 \mathrm{wt} . \%$ of $\mathrm{MoS}_{2}$ has shown a mild wear regime and ploughing. The wear track found can be identified as abrasive wear tracks. Figure 10 shows a film layer of $\mathrm{MoS}_{2}$ that can also be detected on the surface of the composite, which acts as a key factor in preventing the wear at increasing velocity, and comparable results were observed in the previous works (Jojith and Radhika, 2019; David Joseph et al., 2018). 4wt.\% of $\mathrm{MoS}_{2}$ reinforced aluminum alloy reveals severe ploughing and crater formation on the surface. Figure 11 shows that severe delamination is also seen as evidence of abrasive wear mechanism, which was comparable to Jojith and Radhika (2019). The wear mechanism of the composites and the unreinforced aluminum alloy is like a mixed mechanism of the adhesive and abrasive wear mechanism, which could be concluded from the delamination and ploughing in the unreinforced alloy and composites (Figures 9, 10, and 11). Oxidative wear was not formed on any of the composite, and wear debris can be found in the unreinforced aluminum alloy and AA7075+2wt. $\% \mathrm{MoS}_{2}$, which indicates the breakdown of the particles, and similar observations were made by Mohammad Rouhi et al. (2019).

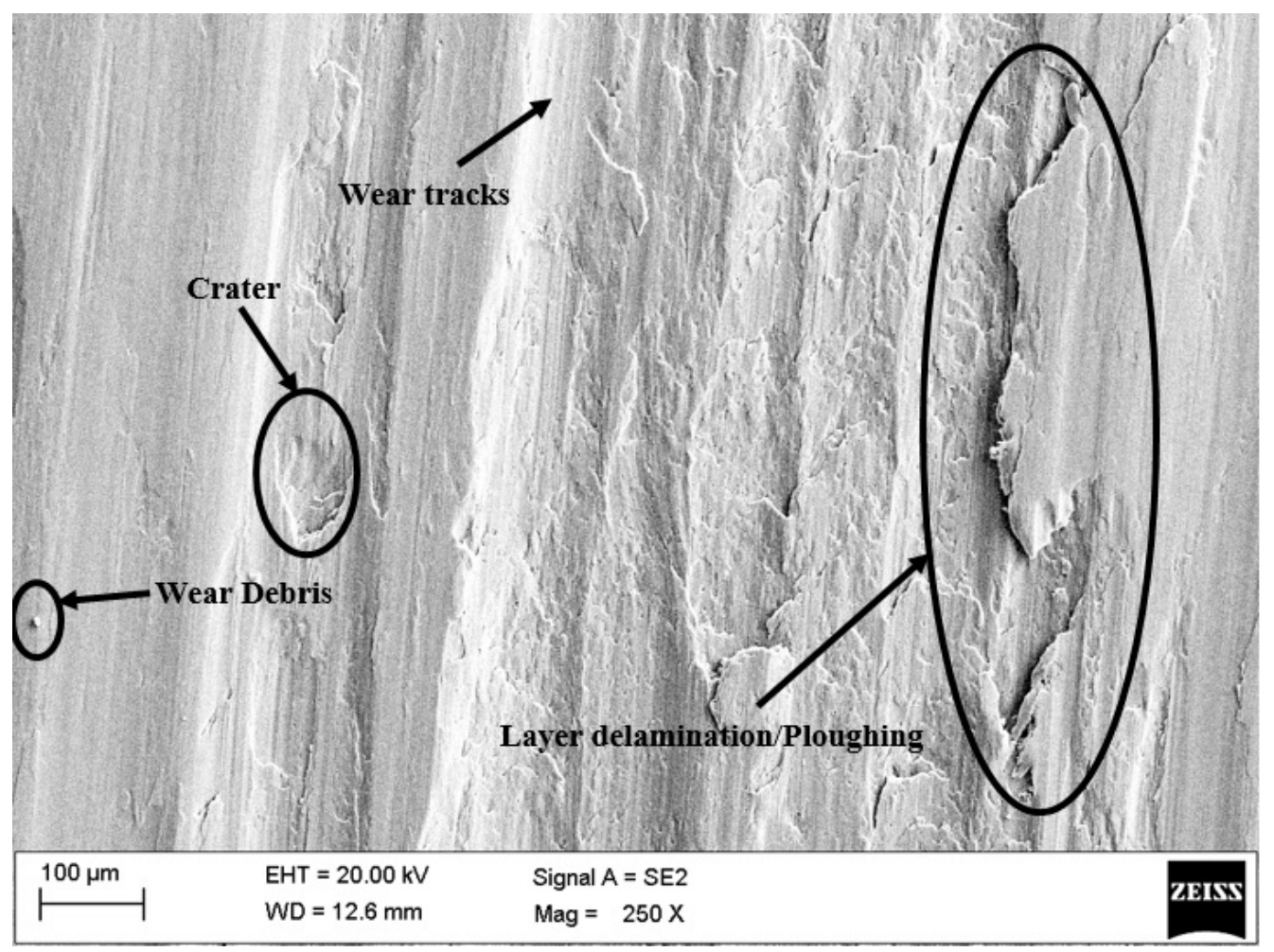

Figure 9. FESEM micrograph of wear surface at $20 \mathrm{~N}$ and $2 \mathrm{~m} / \mathrm{s}$ of AA7075. 


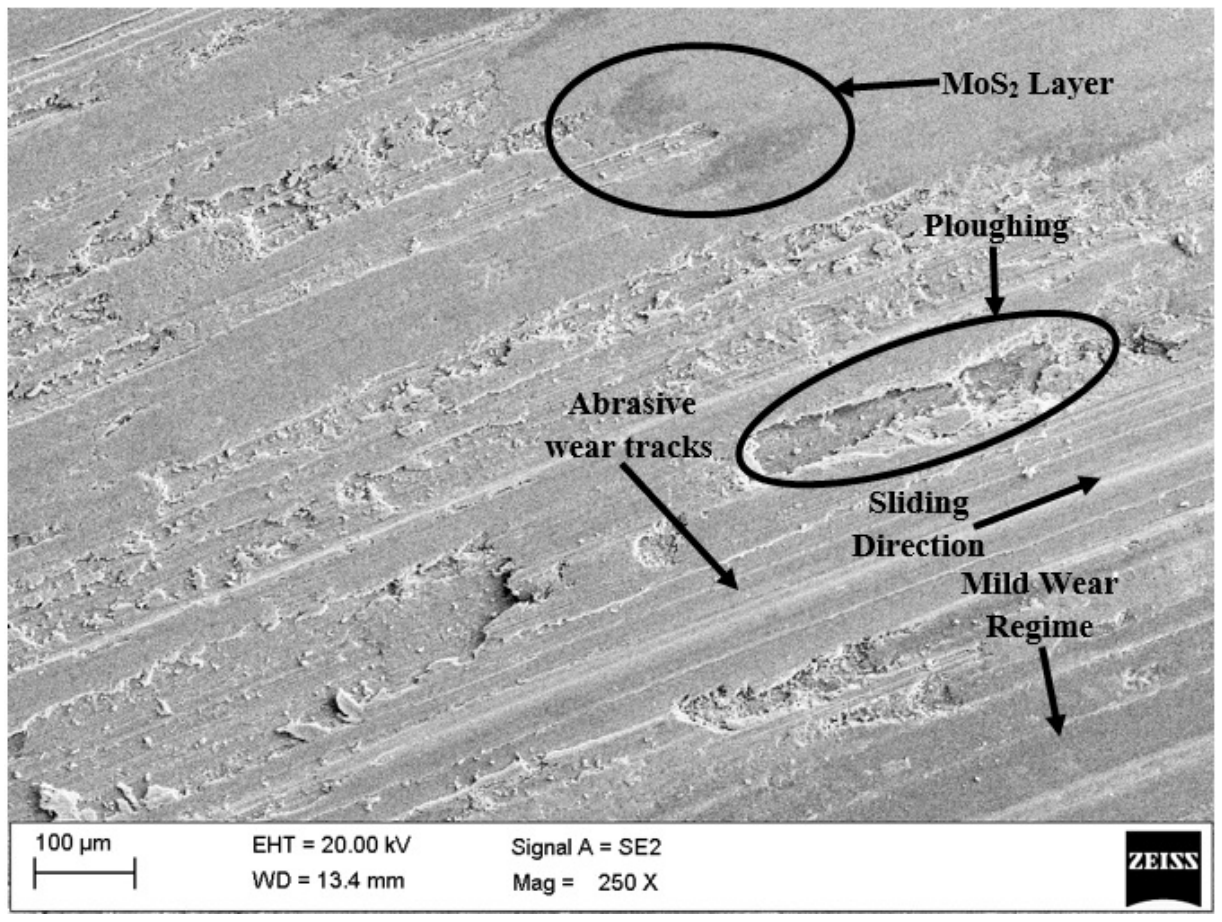

Figure 10. FESEM micrograph of wear surface at $20 \mathrm{~N}$ and $2 \mathrm{~m} / \mathrm{s}$ of AA7075+2wt $\%$ MoS2

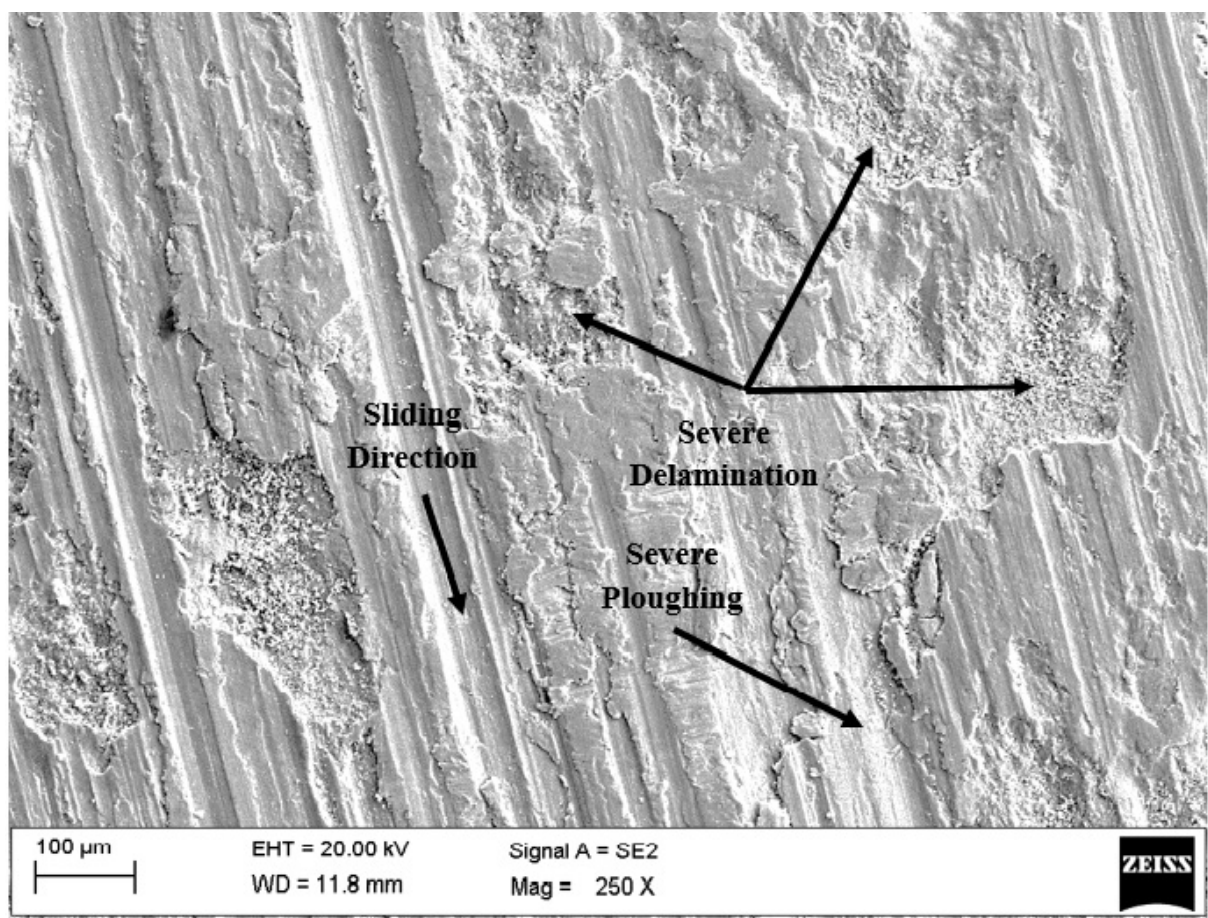

Figure 11. FESEM Micrograph of Wear Surface at $20 \mathrm{~N}$ and $2 \mathrm{~m} / \mathrm{s}$ of AA7075+4wt $\% \mathrm{MoS} 2$. 
The mathematical relationship for correlating the output response (SWR) with the input parameters (namely, percentage of $\mathrm{MoS}_{2}$, sliding velocity, and applied load) is calculated using the regression equation that was obtained. The empirical relation was obtained for the coded terms of the weight percentage of $\mathrm{MoS}_{2}$, sliding velocity, and applied load. It is given as

$S W R=-0.230-0.3676 X 1+0.0517 X 2+0.072 X 3+0.1092 X 1 * X 1-0.001343 X 2 * X 2+0.1000 X 3 * X 3-0.0995$

$X 1 * X 3$

where $\mathrm{X} 1$ is the Weight Percentage of $\mathrm{MoS}_{2}$

$\mathrm{X} 2$ is the applied load.

$\mathrm{X} 3$ is the sliding velocity.

The model summary is shown in Table $5 . \mathrm{R}^{2}$ is the percentage of variation in the response that is explained in the model used to determine the wellness of the model that fits the data. Since $\mathrm{R}^{2}$ is $97.85 \%$, the model is good. The predicted $\mathrm{R}^{2}(92.80 \%)$ is less than the $\mathrm{R}^{2}$ term $(97.85 \%)$, which states that the model is overfitting.

Table 5. Model Summary.

\begin{tabular}{|c|c|c|c|}
\hline S & R-Sq. & R-Sq. (Adj) & R-Sq. (Pred) \\
\hline 0.0698215 & $97.85 \%$ & $96.60 \%$ & $92.80 \%$ \\
\hline
\end{tabular}

The response optimization was taken into consideration to obtain the minimum condition for the specific wear rate. From Table 6, the optimized result of SWR for minimized condition yields the solution of $2.14 \mathrm{wt} \%$ for MoS2, the applied load is optimum for $30 \mathrm{~N}$, and the sliding velocity is $1 \mathrm{~m} / \mathrm{s}$.

Table 6. Solution for Response Optimization.

\begin{tabular}{|c|c|c|c|}
\hline Solution & $\mathrm{M}$ & $\mathrm{L}$ & $\mathrm{SV}$ \\
\hline 1 & 2.14141 & 30 & 1 \\
\hline
\end{tabular}

From the solution, we can conclude that the predicted optimum combinations yield low specific wear rate, and the optimum condition for SWR for AA7075+MoS2 composites is represented graphically in Figure 12. 


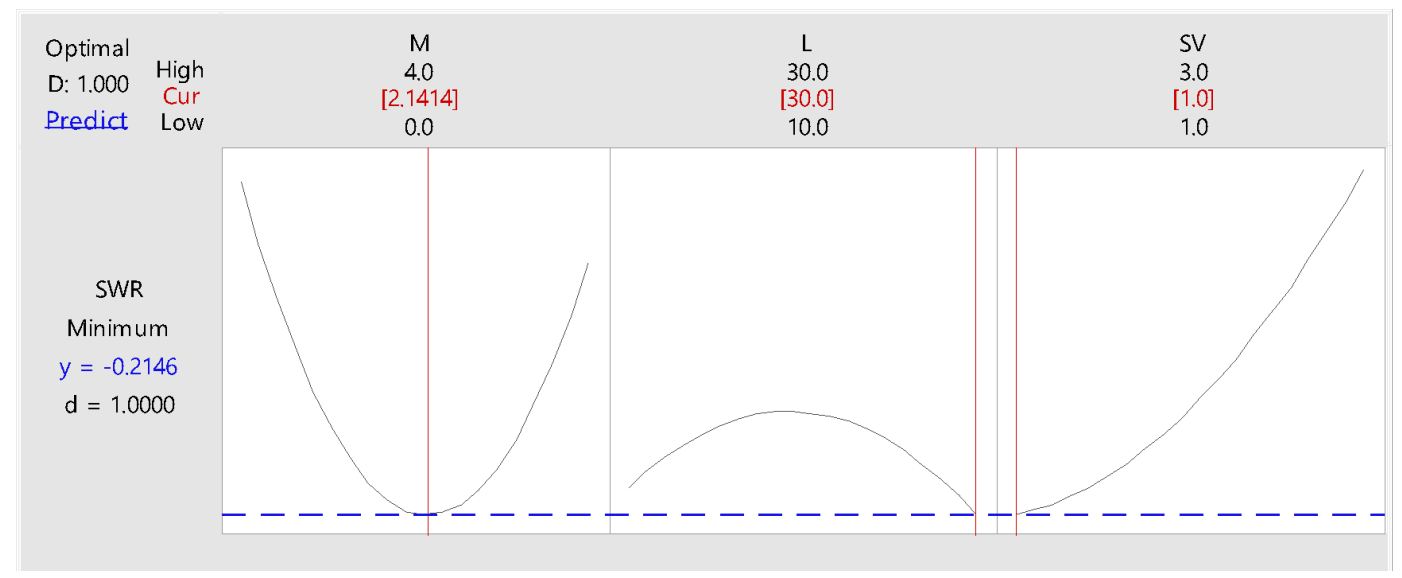

Figure 12. Optimum condition for SWR for AA7075+MoS2 composites.

The confirmation test using the optimum combinations of $2.14 \mathrm{wt} \%$ (approx. $2 \mathrm{wt} \%$ ) of MoS2, $30 \mathrm{~N}$ of applied load, and $1 \mathrm{~m} / \mathrm{s}$ of sliding velocity obtained from Table 6 was conducted. The optimized SWR was obtained as $0.037716 \times 10-3(\mathrm{~m} 3 / \mathrm{Nm})$ through an experiment for the combination of the values in uncoded form for sliding speed, load, and weight percentage of reinforcement. The predicted and experimental values are stated in Table 7. The SEM microimage of wear surface for the optimum condition of applied load $30 \mathrm{~N}$ and sliding velocity $1 \mathrm{~m} / \mathrm{s}$ shows mild wear and mild delamination on the surface of the composite (Figure 13). Worn-out particles can also be seen as a result of the particle breakdown in the composite, and the wear tracks can be identified as an abrasive wear track as Mohammad Rouhi et al. (2019).

Table 7. Result of confirmation test for specific wear rate.

\begin{tabular}{|c|c|c|c|c|c|}
\hline \multirow{3}{*}{ Parameter } & \multirow{2}{*}{ wt $\%$ of $\mathrm{MoS}_{2}$} & \multirow{2}{*}{ Load } & \multirow{2}{*}{$\begin{array}{c}\text { Sliding } \\
\text { Velocity }\end{array}$} & \multicolumn{2}{|c|}{ SWR Value } \\
\hline & & & & \multicolumn{2}{|c|}{$\times 10^{-3}\left(\mathrm{~m}^{3} / \mathrm{Nm}\right)$} \\
\hline & $(\%)$ & (N) & $(\mathrm{m} / \mathrm{s})$ & Predicted & Experimental \\
\hline $\begin{array}{l}\text { Optimum } \\
\text { conditions }\end{array}$ & 2.14 & 30 & 1 & 0.03143 & 0.037716 \\
\hline
\end{tabular}




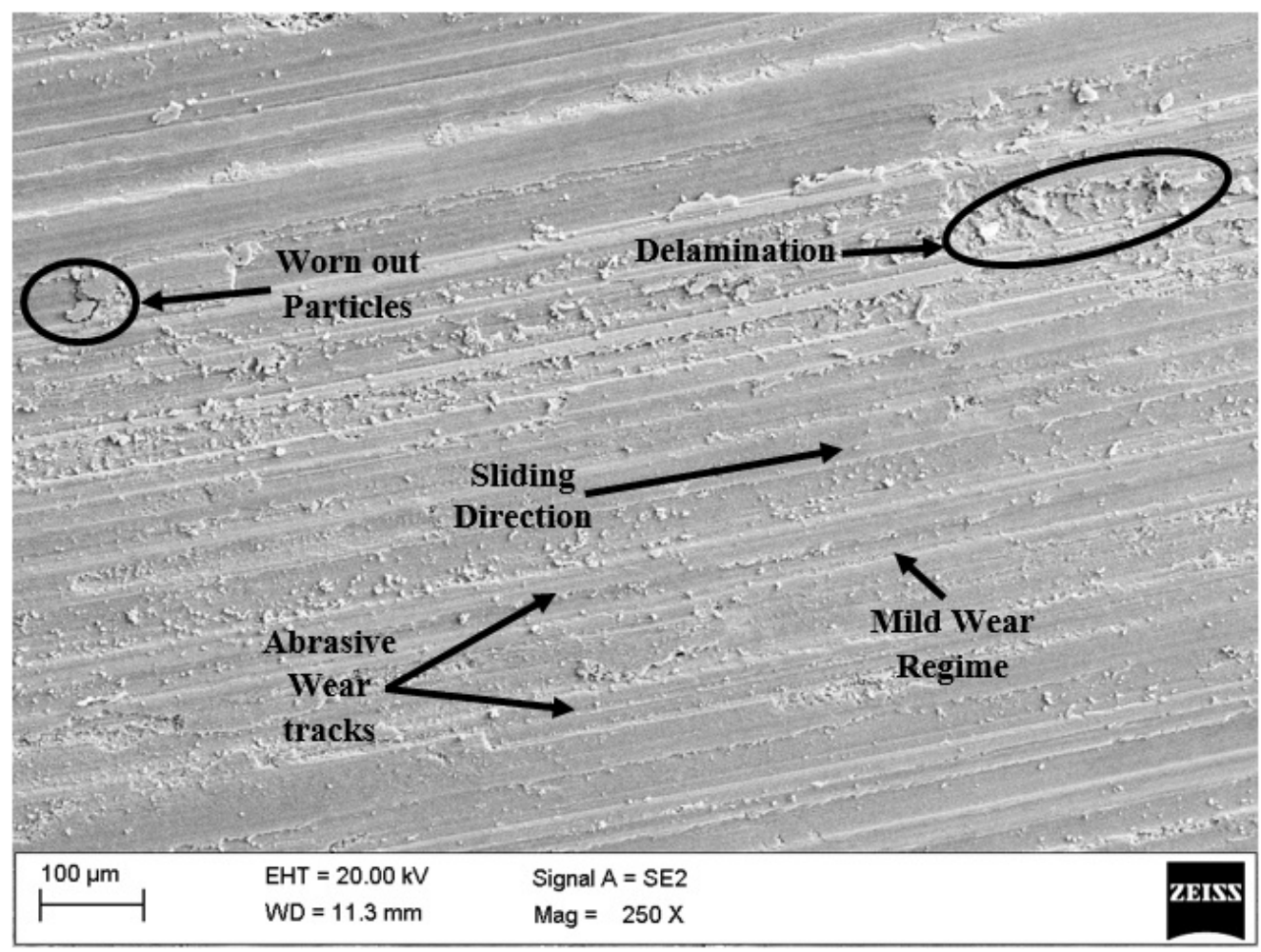

Figure 13. FESEM micrograph of wear surface for optimum condition $30 \mathrm{~N}$ and $1 \mathrm{~m} / \mathrm{s}$ of AA7075+2 $\mathrm{wt} \% \operatorname{MoS} 2$.

\section{CONCLUSION}

This article presents the dry sliding wear investigations of AA7075/MoS 2 , which are summarized as follows:

I. The SEM microimage of the AA7075+2wt. $\% \mathrm{MoS}_{2}$ and AA7075+4wt.\% MoS 2 shows the presence of the reinforcement, $\mathrm{MoS}_{2}$ is distributed homogeneously, and the EDS confirms the traces of the particle reinforcement.

II. The dry sliding wear characteristics are mainly influenced by the presence of $\mathrm{MoS}_{2}$ reinforcement. It is evident that the specific wear rate of the composite decreases with the addition as well as the increment of the $\mathrm{MoS}_{2}$ reinforcement, and only sliding velocity affects the specific wear rate, while the applied load is less significant over the SWR.

III. Based on the ANOVA table, sliding velocity (27.45\%), followed by molybdenum disulfide percentage (24.75\%), employs a noteworthy influence on the specific wear rate of the composites.

IV. The optimum combination for the specific wear rate (SWR) is obtained at the condition $30 \mathrm{~N}$ applied load, $1 \mathrm{~m} / \mathrm{s}$ sliding speed, and $2.14 \mathrm{wt} . \%$ molybdenum disulfide percentage.

V. The SEM microimage for the wear surface of AA7075+2wt.\% MoS 2 and AA7075+4wt.\% MoS 2 shows a mixed mechanism of adhesive wear and abrasive wear, which is commonly studied in aluminum 7075 alloys. For the optimum condition of the composite, mild wear and mild delamination is observed. 


\section{REFERENCES}

Ajith Arul Daniel, S., Sakthivel, M., Gopal, P. M., \& Sudhagar, S. 2018. Study on Tribological Behaviour of $\mathrm{Al} / \mathrm{SiC} / \mathrm{MoS}_{2}$ Hybrid Metal Matrix Composites in High Temperature Environmental Condition. Silicon 10 (5): 2129-2139. DOI: 10.1007/s12633-017-9739-2.

Alidokht, S. A., Abdollah-zadeh, A., \& Assadi, H. 2013. Effect of applied load on the dry sliding wear behaviour and the subsurface deformation on hybrid metal matrix composite. Wear 305 (1-2): 291-298. DOI: 10.1016/j.wear.2012.11.043.

Anish, A. \& Ananth Kumar, M. 2018. Characterization of aluminium matrix reinforced with tungsten carbide and molybdenum disulphide hybrid composite. IOP Conference Series: Materials Science and Engineering 402 (1): 1-9. DOI:10.1088/1757-899X/402/1/012006.

Anish Ranjan \& Shanmugasundaram, A. 2019. Experimental Investigation of Mechanical and Tribological Properties of $\mathrm{Al} 7075-\mathrm{MoS}_{2} / \mathrm{ZrO}_{2} / \mathrm{Ni}$ Hybrid Composite. Advances in Materials and Metallurgy. 299-309. DOI: 10.1007/978-981-13-1780-4.

Bhargavi Rebba \& Ramanaiah, N. 2014. Evaluation of Mechanical Properties of Aluminum Alloy (Al-2024) Reinforced with Molybdenum Disulphide $\left(\mathrm{MoS}_{2}\right)$ Metal Matrix Composites. Procedia Materials Science. 6: 1161 - 1169. DOI: 10.1016/j.mspro.2014.07.189.

David Joseph, J. S., Kumaragurubaran, B. \& Sathish, S. 2019. Effect of $\mathrm{MoS}_{2}$ on the Wear Behavior of Aluminum (AlMg0.5Si) Composite. Silicon 12:1481-1489. DOI: 10.1007/s12633-019-00238-x.

Dharmalingam, S., Subramanian, R., Somasundara Vinoth, K. \& Anandavel, B. 2011. Optimization of tribological properties in aluminum hybrid metal matrix composites using gray-taguchi method 20: 14571466. DOI: $10.1007 / \mathrm{s} 11665-010-9800-4$.

Evans, A., San Marchi, C. \& Mortensen, A., 2003. Metal Matrix Composites in Industry: An Introduction and a Survey. Springer Science+Business Media, US.

Geeta Rani, M., ParameswaraRao, Ch.V.S. \& Rama Kotaiah, K. 2017. Studies on characterization of Al $6061 / \mathrm{MoS}_{2}$ metal matrix composite. International Journal of Mechanical Engineering and Technology 8 (8): 998-1003.

Hemendra Patle, Mahendiran, P., Ratna Sunil, B. \& Dumpala, Ravikumar. 2019. Hardness and sliding wear characteristics of AA7075-T6 surface composites reinforced with $\mathrm{B}_{4} \mathrm{C}$ and $\mathrm{MoS}_{2}$ particles. Materials Research Express 6 (8). DOI: 10.1088/2053-1591/ab1ff4.

International, A., 2005. ASTM G99-05-Standard Test Method for Wear Testing with a Pin-on-Disk Apparatus, ASTM International, West Conshohocken.

Iyandurai, N., Duraisamy. P., Mahendra Boopathi, M. \& Muniyappan, M. 2019. Effect of graphite and molybdenum disulfide on AA 2024 reinforced with slag and calcium carbonate hybrid metal matrix composites. Materials Today: Proceedings. 26 (4): 3615-3622. DOI: 10.1016/j.matpr.2019.09.206.

Jojith, R. \& Radhika, N. 2019. Mechanical and tribological properties of $\mathrm{LM} 13 / \mathrm{TiO}_{2} / \mathrm{MoS}_{2}$ hybrid metal matrix composite synthesized by stir casting. Particulate Science and Technology 37 (5): 566-578. DOI: 10.1080/02726351.2017.1407381.

Kannappan Somasundara Vinoth, Ramanathan Subramanian, Somasundaram Dharmalingam \& Balu Anandavel. 2012. Mechanical and tribological characteristics of stir-cast Al-Si10Mg and self-lubricating Al$\mathrm{Si} 10 \mathrm{Mg} / \mathrm{MoS}_{2}$ composites. Materiali in Tehnologije 46 (5): 497-501.

Mohammad ROUHI, Mohammad MOAZAMI-GOUDARZI \& Mohammad ARDESTANI. 2019. Comparison of effect of $\mathrm{SiC}$ and $\mathrm{MoS}_{2}$ on wear behavior of Al matrix composites. Transactions of Nonferrous Metals Society of China (English Edition) 29 (6): 1169-1183. DOI: 10.1016/S1003-6326(19)65025-9. 
Monikandan, V.V., Joseph, M.A. \& Rajendrakumar, P.K. 2016. Dry sliding wear studies of aluminum matrix hybrid composites. Resource-Efficient Technologies 2 (1): S12-S24. DOI: 10.1016/j.reffit.2016.10.002.

Rajesh Prabha, N. \& Edwin Raja Dhas, J. 2017. Effect of TiC and $\mathrm{MoS}_{2}$ reinforced aluminum metal matrix composites on microstructure and thermogravimetric analysis. Rasayan Journal of Chemistry 10 (3): 729737. DOI: 10.7324/RJC.2017.1031765.

Saini, N., Pandey, C., Thapliyal, S. \& Dwivedi, D. K. 2018. Mechanical Properties and Wear Behavior of Zn and $\mathrm{MoS}_{2}$ Reinforced Surface Composite Al-Si Alloys Using Friction Stir Processing. Silicon 10 (5): 19791990. DOI: 10.1007/s12633-017-9710-2.

Siddesh Kumar, N.G., Ravindranath, V.M. \& Shiva Shankar, G.S. 2014. Mechanical and Wear Behaviour of Aluminum Metal Matrix Hybrid Composites. Procedia materials science 5: 908-917. DOI: 10.1016/j.mspro.2014.07.378.

Somasundara Vinoth, K., Subramanian, R., Dharmalingam, S. \& Anandavel, B. 2014. Optimization of dry sliding wear conditions for AlSi10Mg/SiCp composites using response surface: Genetic algorithm approach. Industrial Lubrication and Tribology 66 (5): 593-600. DOI: 10.1108/ILT-02-2012-0016.

Subba Rao, E. \& Ramanaiah, N. 2017. Influence of Heat Treatment on Mechanical and Corrosion Properties of Aluminum Metal Matrix composites (AA 6061 reinforced with $\mathrm{MoS}_{2}$ ). Materials Today: Proceedings 4 (10): 11270-11278. DOI: 10.1016/j.matpr.2017.09.050. 